\title{
Ferrous sulphate does not directly affect pteroylmonoglutamic acid absorption in rats
}

\author{
BY NORMAN R. C. CAMPBELL ${ }^{1}$, BRIAN B. HASINOFF ${ }^{2}$, MUKHTIAR SINGH $^{2}$ \\ AND SUSAN ROBERTSON ${ }^{1}$ \\ ${ }^{1}$ Divisions of Geriatrics and Internal Medicine, Departments of Medicine and Pharmacology and \\ Therapeutics, Faculty of Medicine, The University of Calgary, Calgary, Alberta, Canada T2N 4N1 \\ ${ }^{2}$ Faculty of Pharmacy, University of Manitoba, Winnipeg, Manitoba R3T $2 \mathrm{~N} 2$
}

(Received 12 May 1993 - Accepted 14 January 1994)

\begin{abstract}
A variety of compounds which bind to Fe have substantial reductions in absorption when co-administered with $\mathrm{Fe}$ compounds. The binding of both $\mathrm{Fe}^{2+}$ and $\mathrm{Fe}^{3+}$ ions to pteroylmonoglutamic acid and the pteroylmonoglutamate dianion was examined in vitro. In dimethylsulphoxide (DMSO) alone, pteroylmonoglutamate formed a 2:1 (pteroylmonoglutamate: $\mathrm{Fe}^{3+}$ ion) complex. However, in DMSO-aqueous Bis-Tris buffer $(4: 1, \mathrm{v} / \mathrm{v} ; \mathrm{pH} 6.0)$ no evidence of complex formation could be seen. Likewise spectroscopic evidence was obtained for complex formation with $\mathrm{Fe}^{2+}$ ion and pteroylmonoglutamate in DMSO alone but not in the aqueous DMSO buffer. In vivo studies examined the effect of $\mathrm{FeSO}_{4}$ on pteroylmonoglutamic acid absorption in an isolated perfused rat jejunal model of nutrient absorption. The dose of pteroylmonoglutamic acid approximated a human dose of $1 \mathrm{mg}$ for the rat, while the $\mathrm{FeSO}_{4}$ doses were chosen to represent $6.4 \mathrm{mg}, 64 \mathrm{mg}$ and $300 \mathrm{mg}$ human doses. There was no significant effect of $\mathrm{FeSO}_{4}$ on pteroylmonoglutamic acid absorption or instability of pteroylmonoglutamic acid in vivo in the presence of $\mathrm{FeSO}_{4}$ in the rat. Although 2:1 binding of pteroylmonoglutamic acid to Fe ions could be demonstrated in DMSO alone, no binding could be demonstrated in DMSO-Bis-Tris buffer $(4: 1, \mathrm{v} / \mathrm{v} ; \mathrm{pH} 6.0)$. It is unlikely that there will be a significant reduction in pteroylmonoglutamic acid absorption during concurrent ingestion of Fe preparations.
\end{abstract}

Drug-nutrient interaction: Nutrient-nutrient interaction: Iron: Pteroylmonoglutamic acid: Complex formation

Several compounds such as thyroxine L-dioxyphenylalanine (L-dopa), methyldopa, penicillamine, tetracycline and quinolone antimicrobials which bind to $\mathrm{Fe}$ have reduced absorption, blood levels or clinical effect when concurrently ingested with Fe supplements (Campbell \& Hasinoff, 1991; Campbell et al. 1992a,b). Pteroylmonoglutamic acid supplements are frequently prescribed (Hillman, 1990) and are recommended to be used by women before and during pregnancy to prevent neural tube defects in the fetus (Czeizel \& Dudas, 1992; Rosenberg, 1992). Fe-replacement therapy is also common (La Piana Simonsen, 1990) and Fe is taken in over-the-counter preparations by many patients. Many multivitamin and mineral preparations contain both $\mathrm{Fe}$ and pteroylmonoglutamic acid (Canadian Pharmaceutical Association, 1992). Concurrent ingestion of pteroylmonoglutamic acid and Fe is therefore likely to be common. Deficiency of Fe predisposes to pteroylmonoglutamate deficiency further increasing the likelihood of concurrent therapy (Vitale et al. 1966). Pteroylmonoglutamic acid forms complexes with a variety of metal ions including $\mathrm{Fe}^{2+}$ (Albert, 1953; Cape et al. 1974; Roos \& Williams, 1977), $\mathrm{Cu}^{2+}$ (Albert, 1953), $\mathrm{Zn}^{2+}$ and $\mathrm{Mn}^{2+}$ (Roos \& Williams, 1977) usually with the formation of $2: 1$ (pteroylmonoglutamate:metal) complexes (Albert, 1953; Roos \& Williams, 1977). From 
the stability constant of the complex of $\mathrm{Fe}^{2+}$ (pteroylmonoglutamate) $)_{2}$ of $\log K_{s}=7 \cdot 9$, at pH 7, approximately $46 \%$ of pteroylmonoglutamic acid would be present in the form of an $\mathrm{Fe}^{2+}$ complex. Thus, pteroylmonoglutamic acid forms a moderately strong complex with $\mathrm{Fe}^{2+}$, and these results suggest that an interaction between pteroylmonoglutamic acid and $\mathrm{Fe}^{2+}$ might occur in vivo (Campbell \& Hasinoff, 1991). Hence, it was decided to look for observable complex formation of both $\mathrm{Fe}^{2+}$ and $\mathrm{Fe}^{3+}$ ions with pteroylmonoglutamic acid under conditions more closely resembling those that might be obtained in vivo and to determine the effect of $\mathrm{FeSO}_{4}$ on pteroylmonoglutamic acid absorption in an isolated perfused rat jejunal model of nutrient/drug absorption.

\section{MATERIALS AND METHODS}

Pteroylmonoglutamic acid absorption was assessed using a standard rat model of nutrient absorption (Meddings \& Westergaard, 1989; Campbell et al. 1993a,b). The study was approved by the Animal Care Committee of the University of Calgary. Groups of six to ten male Sprague Dawley rats (Charles River Canada Inc., St-Constant, Quebec, Canada) weighing 231-312 g were used in the control group and in the experimental groups. The rats were anaesthetized using intraperitoneal urethane at approximately $1.25 \mathrm{~g} / \mathrm{kg}$. Through a mid-line incision immediately distal to the ligament of Treitz, a jejunal segment approximately $50 \mathrm{~cm}$ in length was isolated with sutures. Catheters were inserted into the segment proximally and distally and tied in place. The segments were perfused with $30 \mathrm{ml}$ recycling buffer at $37^{\circ}$. The initial buffer consisted of $120 \mathrm{mM}-\mathrm{NaCl}$ and $50 \mathrm{~mm}$-Bis-Tris (pH 6.0). After $30 \mathrm{~min}, 25 \mathrm{ml}$ buffer was perfused which contained pteroylmonoglutamic acid $(8 \cdot 1 \mu \mathrm{mol} / 1),\left[{ }^{3} \mathrm{H}\right]$ pteroylmonoglutamic acid $(1.4-2.5 \mathrm{nmol} / 1)$, and $\left[{ }^{14} \mathrm{C}\right]$ polyethylene glycol $4000(4 \cdot 2 \mu \mathrm{g} / \mathrm{l})$ with or without $\mathrm{FeSO}_{4}$. The dose of pteroylmonoglutamic acid in the rat was chosen to approximate a human dose of $1 \mathrm{mg}$ on a $\mathrm{mg} / \mathrm{kg}$ basis for the rat assuming: a $70 \mathrm{~kg}$ person, a $0.25 \mathrm{~kg}$ rat and that the total dose was in $10 \mathrm{~cm}$ bowel of rat intestine $(1 \mathrm{ml})$ at all times. The concentrations of $\mathrm{FeSO}_{4}$ used were $6.7,1.43$ and $0.143 \mathrm{mmol} / \mathrm{l}$ and approximated 300,64 and $6.4 \mathrm{mg}$ human doses on a $\mathrm{mg} / \mathrm{kg}$ basis for the rat using the same assumptions as for pteroylmonoglutamic acid. Lumen contents were sampled every $10 \mathrm{~min}$ for $1 \mathrm{~h}$ and were analysed in triplicate in a scintillation counter.

Pteroylmonoglutamic acid concentrations were calculated by multiplying the original pteroylmonoglutamic acid concentration by the $\mathrm{Bq}_{\mathrm{x}} / \mathrm{Bq}_{\mathrm{o}}$ of $\left[{ }^{3} \mathrm{H}\right]$ and were corrected for water absorption and secretion by multiplying the pteroylmonoglutamic acid concentration by $\mathrm{Bq}_{o} / \mathrm{Bq}_{\mathrm{x}}$ of $\left[{ }^{14} \mathrm{C}\right]$ polyethylene glycol $\left(\mathrm{Bq}_{\mathrm{o}}\right.$ is the activity of $\left[{ }^{3} \mathrm{H}\right]$ or $\left[{ }^{14} \mathrm{C}\right]$ at the start of the experiment and $\mathrm{Bq}_{\mathrm{x}}$ is the activity at a given time $\mathrm{x}$ ). Absorption rates were calculated from the slope of the linear regression line derived from the pteroylmonoglutamic acid concentration $v$. time data between 10 and $60 \mathrm{~min}$, were corrected for length of the bowel and are expressed in $\mathrm{pmol} / \mathrm{cm}$ per min.

The stability of pteroylmonoglutamic acid was assessed before perfusion and following perfusion in bowel segments from two animals in each group by HPLC. The HPLC system consisted of a Bio-Rad HPLC pump (model 1330) and a Bio-Rad Biosil ODS 10 reversed phase column (Bio-Rad Laboratories Ltd., Mississanga, Ontario, Canada) heated to $35^{\circ}$. The mobile phase was 0.01 M-triethylammonium phosphate (pH 6.6) with $125 \mathrm{ml}$ methanol/1 solvent. One-minute fractions of HPLC solvent were collected and analysed by scintillation counting. Pteroylmonoglutamic acid eluted in the 4-6 min fractions with the mobile phase run at $1.0 \mathrm{ml} / \mathrm{min}$. The in vivo stability of pteroylmonoglutamic acid in experiments was determined by dividing the percentage of radioactivity eluting under the pteroylmonoglutamic acid peak following perfusion in animals by the percentage of radioactivity eluting under the pteroylmonoglutamic acid peak before perfusion. 


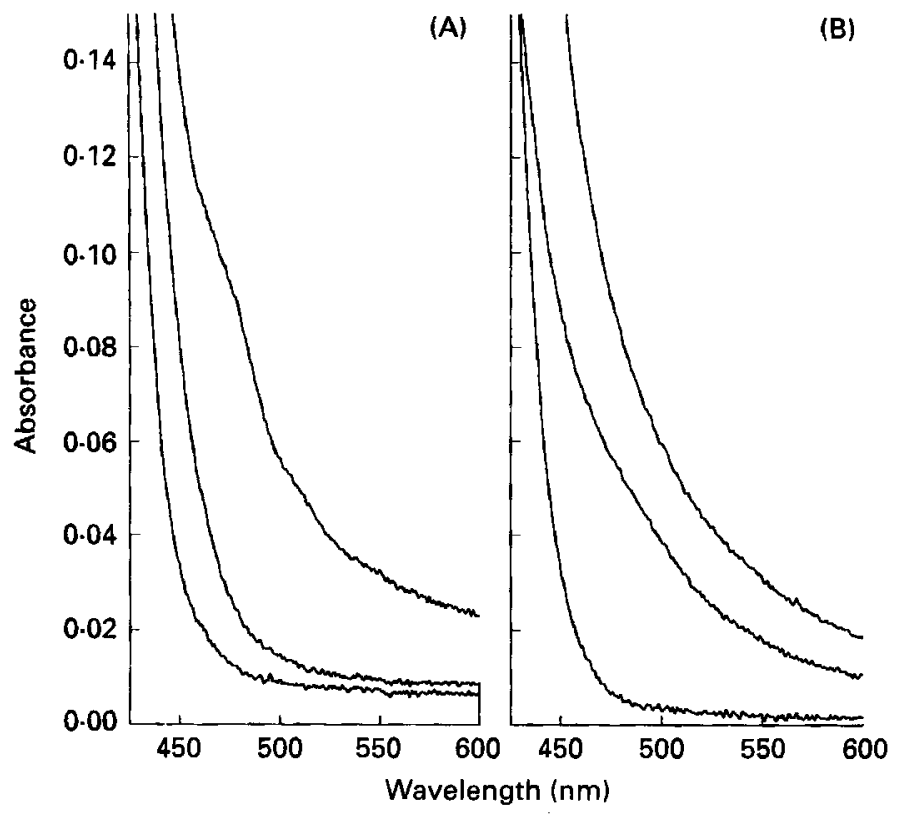

Fig. 1. (A) The visible spectrum of $0.6 \mathrm{mmol} \mathrm{FeCl}_{3} / 1$ (bottom); $1.0 \mathrm{mmol}$ pteroylmonoglutamate $/ 1$ (middle); and a mixture of $0.5 \mathrm{mmol} \mathrm{FeCl}_{3} / 1$ and $1.0 \mathrm{mmol}$ pteroylmonoglutamate/1 (top) in dimethylsulphoxide (DMSO) alone. The spectrum of the mixture displayed a new shoulder at $475 \mathrm{~nm}$ due to formation of a $2: 1$ (pteroylmonoglutamate: $\mathrm{Fe}^{8+}$ ) complex. (B) The legend and conditions are as above, except that pteroylmonoglutamic acid was used instead of pteroylmonoglutamate, and the solvent was DMSO-aqueous Bis-Tris buffer $(4: 1, \mathrm{v} / \mathrm{v} ; \mathrm{pH} 6.0)$. The sum of the spectrum of pteroylmonoglutamic acid and $\mathrm{FeCl}_{3}$ alone is very similar to that of the mixture, which indicates that no observable complex formation occurs.

To characterize the binding of pteroylmonoglutamic acid to $\mathrm{Fe}$, a number of spectrophotometric experiments were carried out in $1 \mathrm{~cm}$ cells on a Cary 1 double beam spectrophotometer with its cell compartment maintained at $25^{\circ}$. Due to the low solubility of pteroylmonoglutamic acid in aqueous buffers, complex formation was looked for in either dimethylsulphoxide (DMSO)-aqueous Bis-Tris buffer $(4: 1, \mathrm{v} / \mathrm{v} ; \mathrm{pH} 6.0)$ or DMSO alone as indicated. The pteroylmonoglutamate dianion was prepared by dissolving pteroylmonoglutamic acid in DMSO and adding $2 \mathrm{~mol}$ aqueous $5 \mathrm{~m}-\mathrm{NaOH} / \mathrm{mol}$ pteroylmonoglutamic acid.

All data are expressed as means with their $95 \%$ confidence intervals. The differences in pteroylmonoglutamic acid absorption with and without $\mathrm{FeSO}_{4}$ were determined by ANOVA. The analysis was performed using Mystat (Systat Inc., Evanston, IL, USA).

For the in vivo studies the urethane, Bis-Tris, $\mathrm{FeSO}_{4}$ and pteroylmonoglutamic acid were obtained from Sigma Chemical Company (St. Louis, MO, USA). For the in vitro spectrophotometric studies anhydrous $\mathrm{FeCl}_{3}$ was obtained from $\mathrm{BDH}$ Chemicals (Toronto, Ontario, Canada), the DMSO (spectrophotometric grade) was obtained from Mallinckrodt (Paris, $\mathrm{KY}, \mathrm{USA}), \mathrm{Fe}\left(\mathrm{NH}_{4}\right)_{2}\left(\mathrm{SO}_{4}\right)_{2}$ was obtained from Fisher Chemical Company (Fair Lawn, NJ, USA), and the pteroylmonoglutamic acid was obtained from Aldrich Chemical Company (Milwaukee, WI, USA). The $\left[{ }^{14} \mathrm{C}\right]$ polyethylene glycol $4000(2 \cdot 22 \mathrm{GBq} / \mathrm{mmol})$ and the $\left[{ }^{3} \mathrm{H}\right]$ pteroylmonoglutamic acid $(1180-962 \mathrm{GBq} / \mathrm{mmol})$ were supplied by Amersham Canada Limited (Oakville, Ontario, Canada). 


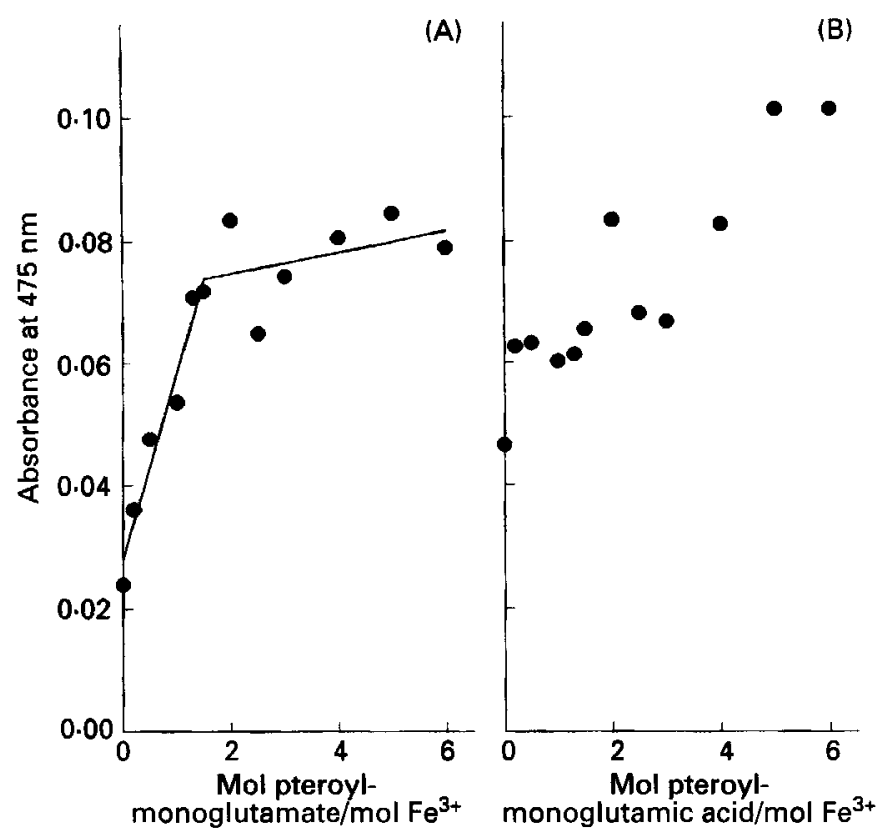

Fig. 2. (A) Spectrophotometric titration of $\mathrm{FeCl}_{3}$ with pteroylmonoglutamate in dimethylsulphoxide (DMSO) alone. The $\mathrm{FeCl}_{3}$ was maintained constant at $0.5 \mathrm{mmol} / 1$, and the pteroylmonoglutamate : $\mathrm{Fe}^{3+}$ ratio was increased by increasing the concentration of pteroylmonoglutamate. The break in the plot at 1.51 (SE 0.22 ) indicates formation of what is most likely a 2:1 (pteroylmonoglutamate: $\mathrm{Fe}^{3+}$ ) complex. (B) The legend and conditions are as above, except that pteroylmonoglutamic acid was used instead of pteroylmonoglutamate, and the solvent was DMSO-aqueous Bis-Tris buffer $(4: 1, \mathrm{v} / \mathrm{v} ; \mathrm{pH} 6.0)$. The lack of any well-defined break in the plot indicates no observable complex formation occurs.

\section{RESULTS}

The average rates of pteroylmonoglutamic acid absorption (mean; 95\% confidence interval) were similar in the absence of $\mathrm{FeSO}_{4}(9 \cdot 5 ; 7 \cdot 6-11.4 \mathrm{pmol} / \mathrm{cm}$ per $\mathrm{min})$ and in the presence of $\mathrm{FeSO}_{4}$ at $0.143 \mathrm{mmol} / 1(10.2 ; 8.4-12.0 \mathrm{pmol} / \mathrm{cm}$ per $\mathrm{min}), 1.43 \mathrm{mmol} / 1(9.2$; $7 \cdot 8-10.6 \mathrm{pmol} / \mathrm{cm}$ per $\mathrm{min})$ and $6.7 \mathrm{mmol} / 1(9.6 ; 7 \cdot 1-12.1 \mathrm{pmol} / \mathrm{cm}$ per $\mathrm{min})$.

The in vivo stability of pteroylmonoglutamic acid was assessed by HPLC. Before perfusion, $96 \%$ of the injected radioactivity eluted in a single peak in the fractions collected between 4 and $6 \mathrm{~min}$. In animals perfused with buffer containing pteroylmonoglutamic acid but no $\mathrm{Fe}$, pteroylmonoglutamic acid was $93 \%$ stable. In two animals perfused with $0 \cdot 143$, 1.43 and $6.7 \mathrm{mmol} \mathrm{FeSO}_{4} /$, pteroylmonoglutamic acid was 100,84 and $100 \%$ stable in vivo respectively.

The addition of $\mathrm{FeCl}_{3}$ to pteroylmonoglutamate (prepared by adding $1 \mathrm{~mol} \mathrm{NaOH} / \mathrm{mol}$ pteroylmonoglutamic acid) resulted in the formation of a reddish precipitate. The spectrum of this precipitate (not shown) had a shoulder at $475 \mathrm{~nm}$, similar to that shown in Fig. 1(A), and is probably due to an $\mathrm{Fe}^{3+}$-pteroylmonoglutamate complex. To avoid experimental problems associated with characterizing this precipitate, spectrophotometric experiments were carried out in DMSO. Since pteroylmonoglutamic acid is soluble in DMSO, the formation of its complex with Fe can be more easily characterized spectrophotometrically. Thus, under these conditions the relative strength of binding and the stoichiometry of the complex formation can be more easily obtained. Upon the addition of anhydrous $\mathrm{FeCl}_{3}$ in DMSO to pteroylmonoglutamate in DMSO, a new spectrum was obtained that exhibited a shoulder at $475 \mathrm{~nm}$ (Fig. 1(A)). This new shoulder, which was not present in either 


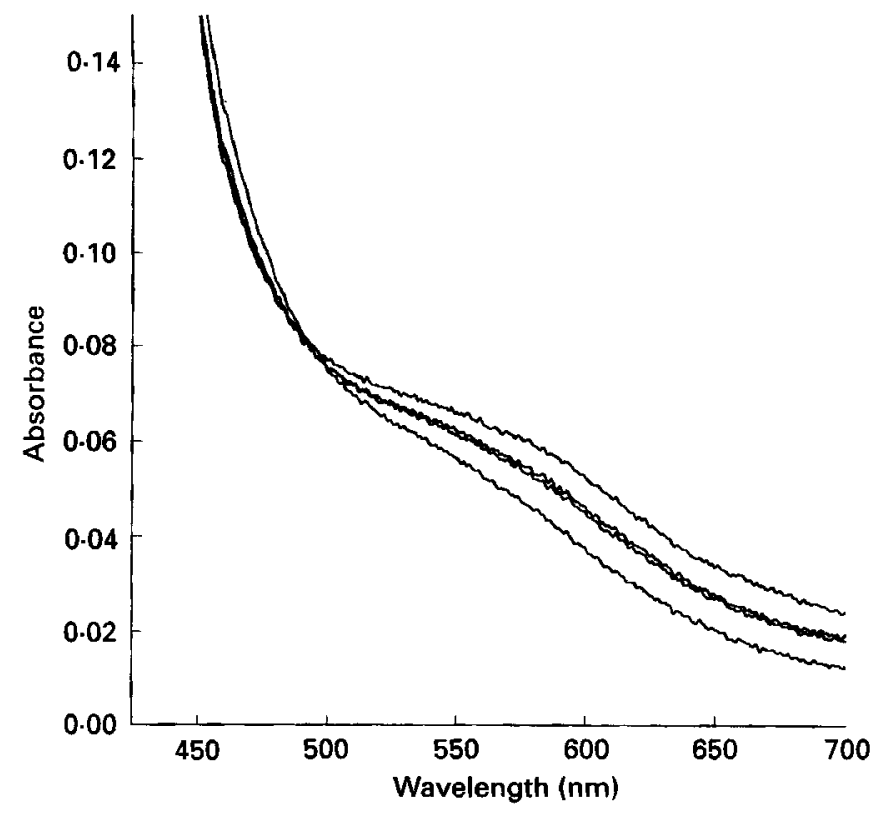

Fig. 3. The visible spectrum of $0.5 \mathrm{mmol}$ ferrous ammonium sulphate $/ 1$ and $1.0 \mathrm{mmol}$ pteroylmonoglutamate $/ 1$ in dimethylsulphoxide alone. The new shoulder at $575 \mathrm{~nm}$ is indicative of a $\mathrm{Fe}^{2+}$-pteroylmonoglutamate complex. The absorbance at $575 \mathrm{~nm}$ decreased with time due to the oxidation of $\mathrm{Fe}^{2+}$-pteroylmonoglutamate. The spectra were recorded at $0.5,2 \cdot 5,4.5$ and $30.5 \mathrm{~min}$ respectively.

pteroylmonoglutamate or $\mathrm{FeCl}_{3}$ (Fig. 1(A)), is indicative of complex formation between $\mathrm{Fe}^{3+}$ and pteroylmonoglutamate. A spectrophotometric titration (Fig. 2(A)) in DMSO only gave a plot with two straight line segments that intersected at 1.51 (SE 0.22) mol pteroylmonoglutamic acid $/ \mathrm{mol} \mathrm{Fe}{ }^{3+}$. This result probably indicates that formation of a $2: 1$ complex is occurring as was previously reported (Albert, 1953; Roos \& Williams, 1977). A small amount of precipitate was seen following complex formation even in DMSO only and this may have led to an intersection point that was less than 2:1. However, in DMSO-aqueous Bis-Tris buffer $(4: 1, \mathrm{v} / \mathrm{v} ; \mathrm{pH} 6.0)$ there was no spectroscopic evidence for complex formation (Fig. 1(B)). Also a spectrophotometric titration (Fig. 2(B)) gave no well-defined intersection point. The increase in absorbance seen with increasing pteroylmonoglutamic acid: $\mathrm{Fe}^{3+}$ molar ratio is due to pteroylmonoglutamic acid alone. Thus at lower $\mathrm{pH}$, corresponding to that which might be obtained in vivo, no evidence for complex formation was obtained. Spectroscopic evidence for complex formation between $\mathrm{Fe}^{2+}$ and pteroylmonoglutamate was also seen (Fig. 3). When pteroylmonoglutamate was mixed with $\mathrm{Fe}^{2+}$ in DMSO only, a spectrum with a new shoulder at $575 \mathrm{~nm}$ was observed. The absorbance of $575 \mathrm{~nm}$ decreased with time probably corresponding to air-oxidation of $\mathrm{Fe}^{2+}$ to $\mathrm{Fe}^{3+}$. However, in DMSO-buffer $(4: 1, \mathrm{v} / \mathrm{v} ; \mathrm{pH} 6 \cdot 0)$, no spectroscopic evidence was found for the formation of an $\mathrm{Fe}^{2+}$-pteroylmonoglutamic acid complex.

\section{DISCUSSION}

In the present study we have shown that both $\mathrm{Fe}^{2+}$ and $\mathrm{Fe}^{3+}$ ions can form a complex with pteroylmonoglutamic acid. However, complex formation could only be seen in DMSO alone or in aqueous solution under basic conditions when a precipitate of the complex was observed to form with the pteroylmonoglutamate anionic species. However, under more 
physiological conditions in DMSO-aqueous buffer ( $\mathrm{pH} 6.0$ ), with a $\mathrm{pH}$ that more closely approximates that found in the gastrointestinal tract, no spectroscopic evidence was found for complex formation with either $\mathrm{Fe}^{3+}$ or $\mathrm{Fe}^{2+}$ ions. Thus, the lack of effect of coadministration of $\mathrm{FeSO}_{4}$ on the absorption of pteroylmonoglutamic acid in the rat is probably due to the low binding ability of $\mathrm{Fe}$ with pteroylmonoglutamic acid under physiological conditions. This observation is important for several reasons. Fe preparations reduce the absorption of many compounds which bind Fe (Campbell \& Hasinoff, 1991; Campbell et al. 1992a,b). Pteroylmonoglutamic acid and $\mathrm{Fe}$ are frequently supplemented in pregnant woman to reduce the incidence of neural tube defects (Czeizel \& Dudas, 1992) and Fe deficiency respectively. A reduction in pteroylmonoglutamic acid absorption could therefore have serious consequences during pregnancy. Pteroylmonoglutamic acid is also supplemented in patients with anaemia secondary to pteroylmonoglutamic acid deficiency and an Fe interaction reducing pteroylmonoglutamic acid absorption could adversely affect patients treated with both agents. Finally, the combination of pteroylmonoglutamic acid with $\mathrm{Fe}$ salts in a tablet would be irrational if $\mathrm{Fe}$ salts caused substantial reductions in pteroylmonoglutamic acid absorption.

This animal model has been used to demonstrate a significant $\mathrm{Fe}$-cimetidine interaction and a nonsignificant interaction between $\mathrm{FeSO}_{4}$ and phenytoin (Campbell et al. 1993a, b). As this model overestimated the extent of the cimetidine- $\mathrm{FeSO}_{4}$ interaction relative to results obtained in humans (Partlow et al. 1993), it is unlikely there will be a clinically important interaction between $\mathrm{FeSO}_{4}$ and pteroylmonoglutamic acid in humans.

Pteroylmonoglutamic acid and the pteroylmonoglutamic acid:Fe complex have several characteristics suggested to favour Fe reducing pteroylmonoglutamic acid absorption (Campbell \& Hasinoff, 1991). The pteroylmonoglutamic acid:Fe complex is poorly soluble even in DMSO alone. Precipitation of complexes is likely to contribute to reduced bioavailability (Campbell \& Hasinoff, 1991). Further, not only is Fe formulated in the same tablet as pteroylmonoglutamic acid but the high molar ratio of $\mathrm{Fe}$ :pteroylmonoglutamic acid in most formulations strongly favours binding of pteroylmonoglutamic acid (Campbell \& Hasinoff, 1991). The results of the present study are consistent with the hypothesis that the strength of the Fe complex formation is a major determinant of whether a significant Fe interaction will occur (Campbell \& Hasinoff, 1991). Even in the presence of other factors favouring interaction it appears that the $\log$ stability constant of the complex must be higher than 7.9 before a substantial interaction will occur. Fe can also catalyse oxidation and reduction reactions, irreversibly altering compounds (Campbell \& Hasinoff, 1991). However, the chemical stability of pteroylmonoglutamic acid in the presence of $\mathrm{Fe}$ ions is also against a demonstrable interaction reducing pteroylmonoglutamic acid absorption.

We could not demonstrate a significant effect of $\mathrm{FeSO}_{4}$ on pteroylmonoglutamic acid absorption in an animal model demonstrated to be sensitive to the presence of $\mathrm{Fe}$ interactions (Campbell et al. 1993 a; Partlow et al. 1993). Further, we could not find evidence of a significant chemical interaction between pteroylmonoglutamic acid and $\mathrm{Fe}$ ions even in a partially aqueous solution. It is unlikely that concurrent ingestion of pteroylmonoglutamic acid with $\mathrm{FeSO}_{4}$ or the inclusion of pteroylmonoglutamic acid with Fe salts in a tablet will significantly reduce pteroylmonoglutamic acid absorption.

We would like to thank Heather Arcari for her expert secretarial assistance. Dr $\mathrm{N}$. Campbell is supported by the Brenda Strafford Foundation. This work was funded in part by grants from the Natural Sciences and Engineering Research Council of Canada (BBH) and the Medical Research Council of Canada (BBH). 


\section{REFERENCES}

Albert, R. A. (1953). Quantitative studies of the avidity of naturally occurring substances for trace metals. Biochemical Journal 54, 646-654.

Campbell, N. R. C. \& Hasinoff, B. B. (1991). Iron supplements: a common cause of drug interactions. British Journal of Clinical Pharmacology 31, 251-255.

Campbell, N. R. C., Hasinoff, B. B., Meddings, J. B., Anderson, W. B., Robertson, S. \& Granberg, K. (1993a). Ferrous sulfate reduces cimetidine absorption. Digestive Diseases and Sciences 38, 950-954.

Campbell, N. R. C., Hasinoff, B. B., Robertson, S. \& Singh, M. (1993 b). Absence of an effect of ferrous sulfate on phenytoin absorption. Clinical and Investigative Medicine 16, 280-284.

Campbell, N. R. C., Hasinoff, B. B., Stalts, H., Rao, B. \& Wong, N. (1992a). Ferrous sulfate reduces thyroxine efficacy in patients with hypothyroidism. Annals of Internal Medicine 117, 1010-1013.

Campbell, N. R. C., Kara, M., Hasinoff, B. \& McKay, D. W. (1992b). Norfloxacin interaction with antacids and minerals. British Journal of Clinical Pharmacology 33, 115-116.

Canadian Pharmaceutical Association (1992). Compendium of Pharmaceuticals and Specialties, 27th ed. [C. M. E. Krogh, editor]. Ottawa: Canadian Pharmaceutical Association.

Cape, J. N., Cook, D. H. \& Williams, D. R. (1974). Thermodynamic considerations in co-ordination. Part XIX. In vitro studies of complexing equilibria involved in oral iron (II) therapy. Journal of the Chemistry Society (Dalton Trans) 1849-1852.

Czeizel, A. E. \& Dudas, I. (1992). Prevention of the first occurrence of neural-tube defects by periconceptional vitamin supplementation. New England Journal of Medicine 327, 1832-1835.

Hillman, R. S. (1990). Drugs effective in iron-deficiency and other hypochromic anemias. In Goodman and Gillman's The Pharmacological Basis of Therapeutics, 8th ed., pp. 1277-1310 [A. G. Gilman, T. W. Rall, A. S. Nies and P. Taylor, editors]. New York: Pergamon Press.

La Piana Simonsen, L. (1990). Top two hundred drugs of 1989. Pharmacy Times 56, 56-64.

Meddings, J. D. \& Westergaard, H. (1989). Intestinal glucose transport using perfused rat jejunum in vivo: model analysis and derivation of corrected kinetic constants. Clinical Science 76, 104-113.

Partlow, E., Chan, S. C., Pap, K. M. \& Campbell, N. R. C. (1993). The effect of ferrous sulfate on cimetidine absorption in healthy volunteers. Clinical Pharmacology and Therapeutics 53, 163 (Abstr).

Roos, J. T. H. \& Williams, D. R. (1977). Formation constants for citrate-, folid acid-, gluconate-, and succinateproton, -manganese (II) and -zinc (II) systems: relevance to absorption of dietary manganese, zinc and iron. Journal of Inorganic and Nuclear Chemistry 39, 367-369.

Rosenberg, I. H. (1992). Folic acid and neural tube defects - time for action? New England Journal of Medicine 327, 1875-1876.

Vitale, J. J., Restrepo, A., Velez, H., Riker, J. B. \& Hellerstein, E. E. (1966). Secondary folate deficiency induced in the rat by dietary iron deficiency. Journal of Nutrition 88, 315-322. 